\title{
MAKING THE LOGIC: A METHODOLOGICAL EXPERIENCE OF DIGITAL DESIGN PROCESS FOR SMALL URBAN INTERVENTIONS
}

\section{CONSTRUINDO A LÓGICA: UMA EXPERIÊNCIA METODOLÓGICA DE PROCESSO DE PROJETO DIGITAL PARA PEQUENAS INTERVENÇÕES URBANAS}

\author{
Megg Sousa ${ }^{1}$, Denise Mônaco dos Santos ${ }^{1}$, Andressa Martinez ${ }^{1}$, Douglas Souza ${ }^{1}$
}

\section{ABSTRACT:}

The emerging digital design process discourses point to the growing need to connect and manipulate design objective data. One of the challenges is knowing how to relate and operationalize this data accurately using a computational environment. The purpose of this article is to investigate digital design processes by developing a design logic for small urban projects using objective data. The process developed is based on (1) defining the project location criteria, according to georeferenced data and the Space Syntax theory; (2) operationalizing the socio-spatial relations according to the book A Pattern Language; (3) developing a Grasshopper definition for modeling several families of objects. We tested the method in a small urban intervention, in the city of Viçosa (MG), with the purpose of digitally producing a piece of urban furniture.

KEYWORDS: data-driven design; A Pattern Language; space syntax; urban digital design

\section{RESUMO:}

Os discursos emergentes de processo digital de projeto apontam a necessidade crescente de conectar $e$ manipular dados objetivos de projeto. Um dos grandes desafios é saber como relacionar e operacionalizar estes dados de forma coerente, utilizando ambiente computacional. O objetivo deste artigo é investigar processos de projeto digitais através do desenvolvimento uma lógica projetual para pequenas intervenções urbanas usando dados objetivos. O processo desenvolvido se baseia em (1) definir critérios de localização da intervenção, a partir de dados georreferenciados e métricas baseadas da teoria da sintaxe espacial; (2) operacionalizar as relações socioespaciais do livro Uma Linguagem de Padrões; (3) definir um algoritmo visual em Grasshopper para a modelagem da tectônica de soluções. Os resultados foram obtidos a partir da aplicação do método em uma situação real de pequena intervenção urbana na cidade de Viçosa (MG), para a fabricação de mobiliário urbano.

PALAVRAS-CHAVE: projeto orientado por dados; Uma Linguagem de Padrões; sintaxe espacial; projeto urbano digital.
Fonte de Financiamento: Fundação de mparo à Pesquisa de Minas Gerais FAPEMIG.

Conflito de Interesse: Declara não haver.

Ética em Pesquisa: Declara não haver necessidade.

Submetido em: 06/04/2021 Aceito em: 17/08/2021

How to cite this article:

SOUSA, M.; SANTOS, D. M. dos; MARTINEZ, A.; SOUZA, D.. Making the logic: a methodological experience of digital design process for small urban interventions. Gestão \& Tecnologia de Projetos. São Carlos, v17, n1, Ano 2022. https://doi.org/10.11606/gtp.v17i1.181763 


\section{INTRODUCTION}

Regardless of the intervention scale, the design process in architecture and urbanism has a complex and heterogeneous character, resulting from the connection of several aspects, which feed each other constantly. The emerging discourses of digital design are aligned to a systemic, parametric, algorithmic, and topological perspective, in which the designer focuses less on the development of the architectural object and more on the established connections (CARPO, 2017; KOLAREVIC, 2003). Therefore, the connection of design data in an objective, mathematical and logical way becomes the main design strategy (KOTNIK, 2017).

In this context, this paper presents action research for small urban interventions that use computational logic as a method of collecting, analyzing, and using data. As methodological instrument, it seeks to relate local georeferenced data, associated with the analytical and predictive method of Space Syntax theory, Christopher Alexander's patterns logic, combined with an algorithmic visual modeling environment (Grasshopper). Beyond a complete process, this paper presents a reflection about the potential and limitations of each tool and method, indicating possible perspectives in combining different approaches to design urban furniture.

We developed this work at the Federal University of Viçosa following the presented method steps: (1) Defining the position of the object, from readings with georeferenced data and confrontation with the Space Syntax theory; (2) Operationalizing socio-spatial and topological relations in the book A Pattern Language (ALEXANDER; ISHIKAWA; SILVERSTEIN, 1977) to define scope of the design approach; (3) Defining a visual algorithm in Grasshopper for tectonic modeling of parametric solutions set for urban furniture, digitally produced.

\section{BACKGROUND}

The future of urban design is connected to the application of data set as input, in contrast to the exclusive use of guidelines and projects coded based on empirical and heuristic rules (KVAN, 2020). There is an increasing flow of data production, more and more consistently, but there is a shortage of planners who are able to combine the analysis capacity of these data systems with the urban design knowledge. Works like City Induction (DUARTE et al., 2012) and CityMaker (BEIRÃO, 2012) are on this path, because they allow the designer to compose a design solution from a set of relations that could be measured, and also CityMetrics (LIMA et al., 2019), that articulates performance evaluation metrics and algorithmic-parametric features to analyze and optimize the operation possibilities of geometric and algebraic configurations of a given urban area. The data represents the technical, social, and formal requirements and attributes that the designer manipulates to make the design coherent. They can be related to thermal-acoustic-structural performance, functionality, regulations and legislation, budgetary issues, demographic data, materiality and tectonics, displacements and so much other relevant information to the urban and architectural context. As the data are multiple, the way the designer operationalizes them influences all other aspects, such as the tools, the project scale, and even the cognitive character. Some data, according to Kvan (2020), come from intentional records (traffic counts and tax records), ephemeral data (Twitter feeds), or inferred (from image analysis).

Increasingly, open data is disclosed by institutions and governments in response to transparency and accountability demands (KVAN, 2020). From all the information available, the designers need to select, verify, and treat only the relevant data, according to the project. As this information alone is insufficient to provide more efficient responses to cities, there is a need for well-structured theoretical support for planners' decisions. Just as architecture 
incorporated scripts to generate new geometries, it is possible to incorporate them into urban planning.

One of the challenges of contemporary planning is to find ways to articulate users' needs, apparently empirical and subjective, with data of a more technical nature (PICON, 2015). The contemporary methodological challenge is operationalizing urban data with those cultural values, such as human behavior and social dynamics. Thus, as this paper aims to develop a more explicit design logic through the combination of data from different natures, so does the theoretical background go through a correlation between georeferenced data, syntactic analysis, user-oriented design, and tectonics.

\section{GEOGRAPHIC INFORMATION SYSTEM (GIS)}

With the massive use of GPS associated with the most diverse fields of knowledge and society, data production arouses in architects and urban planners a particular interest in geospatial data related to space and time, incorporating location information (HE, 2020). One of the most widespread computational work methodologies is the Geographic Information System (GIS). In architecture and urbanism, GIS has become essential to manage cities, despite the lack of information in small Brazilian cities. As it is a system of coordinates, we can use the GIS in several media, with various programs, and ease the way to digital manufacturing and prototyping (SANTOS et al., 2016).

\section{SPACE SYNTAX}

Space syntax as a static model to indicate dynamics is simple and robust, as it generates data that allows a quick syntactic analysis (VAN NES; YAMU, 2017). By definition, Space syntax (SS) is a set of theories developed by Bill Hillier and colleagues at University College London in the 1980s, which parses a part of the morphological structure of the space built using different metrics. (HILLIER; HANSON, 1984) suggest that the configuration of urban areas affects the routes people choose in the city. According to Ratti (2004), this versatile urban analysis also became a simulation method, allowing the comparison between projects, generating results that are valuable feedback for designers. However, although the Space Syntax is related to physical spatial city configuration, the analysis also depends on other social processes and human behavior (VAN NES; YAMU, 2017). Despite the prior use in the 1980s, the evolution of studies and software has shown results regarding its combination with other analytical methods. Examples such as the recent study for the intensification of urban density and quality in the city of Bergen, Norway, combine Space Syntax with measures of urban density, land use and occupation, and public transport (DE KONING et al., 2017).

According to Lima et al. (2018), the central idea of space syntax comes from observing the city by integrating physical attributes and social interactions, with the possibility of decomposing spaces into components, analyzing and generating them graphically. The three basic foundations of SS are the concepts of convex space, axial space, and isovist. The convex space is what can be represented by a polygon or convex solid, empty, and occupied. The axial space, derived from the convex space, can be synthesized with one or more straight lines. The isovist space consists of a polygon of the field of vision of a location (LIMA et.al 2018). The most used software for analysis is Depthmap®, which exports files in *.mif format, in addition to *.txt, which allows the association with ArcGIS $®$ attributes in an interface with GIS. We represent the visualization maps of the calculations on a hot-cold scale, in which red characterizes the areas of more 'pedestrian movement' on streets.

The SS analysis are related to syntactic measures: Connectivity, Depth, Control, Integration, and Choice. Connectivity results from the lines that intercept it, measuring the number of 
connections. 'Depth' measures the number of topological steps, which means the distance between neighboring spaces needed to reach another point. 'Control' measures the degree of choice each place represents for its immediate neighbors, their dependence on spatial accessibility. The 'Integration' describes the average topological depth of an axial line with all the others remaining in the system (LIMA et al. 2018). The measures mentioned above are first order measures, but it is also possible to generate second-order measures by associating the primary metrics.

Despite the increasing use of Space Syntax, Ratti (2004) points out some controversial points in this analysis. The first is the two-dimensional representation of the urban layout. It ignores the three-dimensional city information, such as the width, street slope, and the heights of the buildings. For this reasoning, some researchers developed methods as an alternative to weighing the factor of the third dimension by adding mathematical formulas (KIM; KIM; KIM, 2019). The second argument is the topological representation in opposition to the geometric one, discarding the metric information in the pedestrian's decision-making. Ratti (2004) signaled other limitations, such as the not considering the land use and occupation through the pedestrian movement.

In contrast, Netto (2016) clarifies some elements that the SS does not propose to explain or to be. First, SS is not a theory capable of explaining what the city is and its transformations. It is also not a "spatial theory of society" but a "theory of the social logic of space" seeking information and social content that the configuration of places carries. It is not a mathematical theory of space. It would be unfair to reduce it to a "mathematization of the obvious" because the knowledge of the relationship between movement and urban structure is only clear from the urban experience. The syntax is far from being self-evident. It is a great ally to be used with other data layers in the city (NETTO, 2016).

\section{A PATTERN LANGUAGE}

Intending to interpret users' desires and promote a dialogue between professionals and lay people in participatory processes, the work "A Pattern Language" sought to identify timeless characteristics of the space conformation, construction, and rescue the local scale between people. The book is an attempt to reveal and demystify socio-spatial considerations through organized design patterns for easy consultation and, above all, to show the interconnection of these patterns in a system. The book "A Pattern Language" emerged amid criticism of modernist architecture and urban planning, also questioned in the 1960s and 1970s by authors such as Jacobs (1961) and Whyte (1980). According to Dawes and Ostwald (2017) in the book "The Timeless Way of Building", Christopher Alexander (1979) details what he calls "the city's unnamed quality". According to Alexander, a "pure" and genuine quality marked by beauty and inherent occupation in traditional cities, which provides a cohesive design language that is an idea that grounds the pattern. 


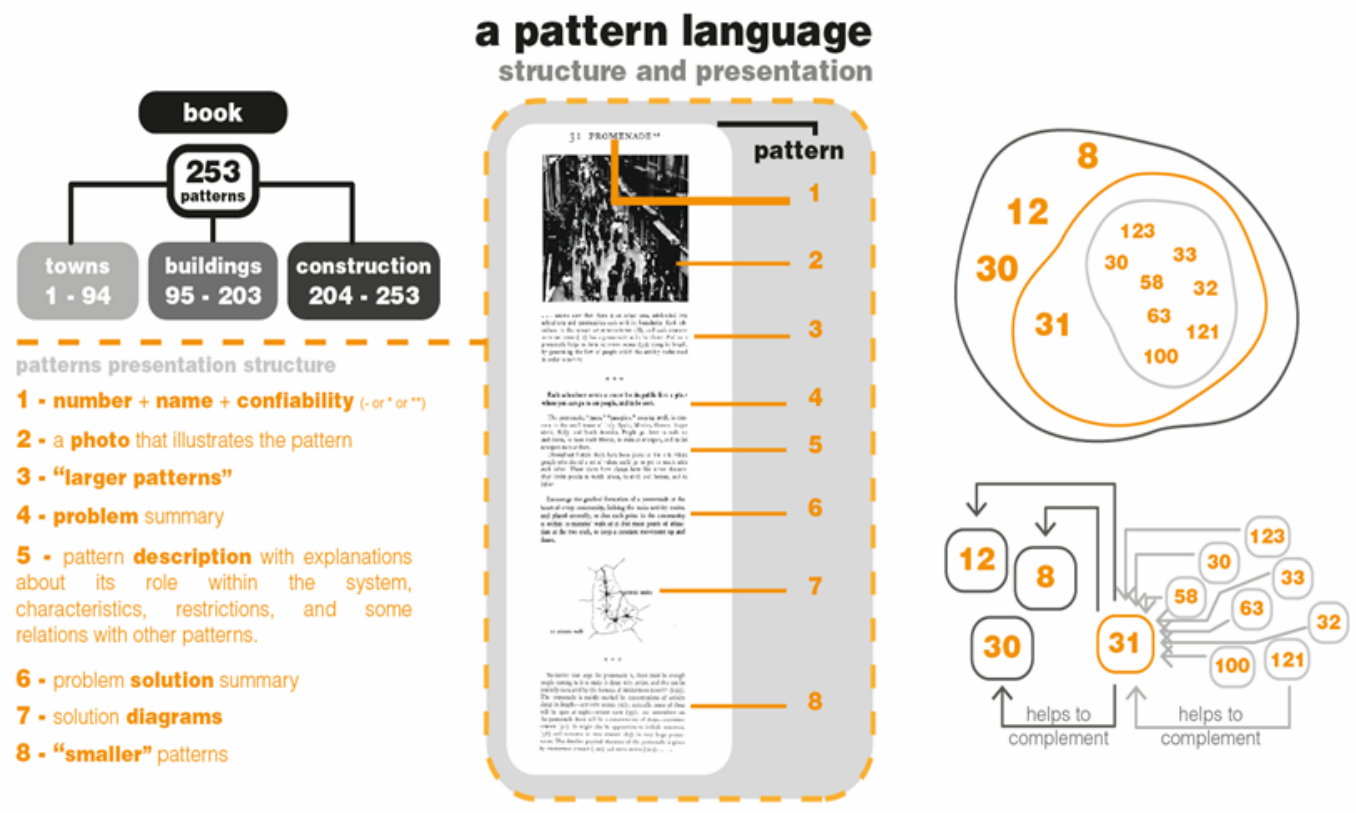

Figure 1. Structure of the book "A Pattern Language"

Source: Authors

The book presents a set of 253 patterns organized into three classes (Figure 1): towns (patterns 1 to 94), buildings (95 to 204), and construction (205 to 253). The Patterns' presentation follows a uniform order and organization. First, the pattern number, name, and asterisks are presented, indicating its reliability, that is, how the solution of the problem describes the deep and inevitable properties of a well-shaped environment. In sequence, in some patterns, a photo appears to illustrate how it works in a real situation. The text is divided into parts; initially, the interconnected patterns that form the grounds for it to happen are presented, that is, the "larger patterns", with a broader scope. In sequence, there is a paragraph that best summarizes the problem. In the text box, the characteristics, restrictions, and relations with some patterns are detailed. Below, another highlighted paragraph describes the solution and some even have synthesis diagrams. In the end, the "smaller patterns" are presented, secondary patterns that complement the described pattern.

This characteristic of the relation between "larger patterns" and "small patterns" can be represented by mathematical sets (Figure 1) or by a matrix of connections which also demonstrates a connection to mathematical and topological thinking about space. The patterns form languages, creating coherence in a region, city, or buildings from patterns that, complemented and combined in different ways, generate infinite variations. Alexander et al. (1977) make an analogy with a poem, which are words organized in order to generate meaning, new semantics. Using patterns does not guarantee good designs; the most crucial point is how they are used together, interconnected to form a language.

As well as it has been defended and discussed over the years, the book has also been widely criticized. One of the criticisms concerns the universal character of the work, with the idea that all regions share a set of values, ways of life, local influences showed on the patterns, that is, a "romanticized" world vision. But, the authors themselves make it clear that the patterns are a starting point. So, people can build their own language, according to local characteristics, including modifying some patterns or adding new ones. Another criticism according to Park and Newman (2017), in the book, it is not clear how to discard some patterns with coherence, in addition to the difficulty of finding which ones are the most important, as some even occupy up to nine pages, which makes it difficult to manipulate the whole, so important to the idea of the network inserted by the authors. Despite the possible obsolescence, "A Pattern Language" is still relevant as an investigation topic because it was one of the most significant public space 
studies of its time (GEHL; SVARRE, 2013). Currently, this study is incorporated and adapted to new contemporary approaches. According to Park and Newman, (2017) the relevant merit of the text is the connectivity between patterns, in which users can easily expand the potential of their design from these connections.

\section{material based design (MBD)}

According to Paoletti and Nastri (2021), the material is the first and last substance of any design process, but we are going through an era of profound mutations. The priority is in the way we design and produce our built environments and the relationship between technology and materials can drive this change. The authors defend the need for a "material balance" in the practice of design, not only from an energetic and environmental perspective but also from a physiological, cultural, and semantic perspective. A new responsible material culture, supported by computational tools, could design innovative and accurate material systems, but with awareness of environmental and human impacts. Thus, the material also becomes an input, an essential design data, in the reality of digital manufacturing and processes.

The conventional tectonic order of architecture has been changed from form-structurematerial to material-structure-form, creating new ways of thinking about the project, which Oxman (2012) named as material-based design. Tectonic relationships are present from conception to fabrication, in an explicit flow of computational information that increases the relationships between form, structure, and material properties (OXMAN, 2017). According to her, tectonics is becoming a seminal concept, due to the ease of mediation between manufacturing and design. Materiality mutually informs the tectonic components in the design process, promoting change through prototyping and manufacturing, not just assembly techniques.

The conventional designation is that the architects conceive the project, and later it is structured and materialized with the collaboration of an engineer. In the new design approaches, this collaboration does not happen at the final steps but in the conceptual and generative stages. The topological relationship between shape, structure, tectonics, and manufacturing models, with parametric design, also enabled the design of complex forms (OXMAN, 2017). According to Scheeren and Sperling (2018), experiments with materials change the focus from shape to matter, in investigations that do not abandon the conceptual and symbolic character.

\section{METHOD}

This work demonstrates how we designed the process, to understand the local conditions and how we correlated the data to translate users' wishes to others of technical, spatial, and tectonic aspects. From these analyses, we applied the design method in a concrete situation, illustrating the particularities in data collection, the local conditions, and execution limitations. At the end, we developed a physical artifact to be implemented in the locality.

Since the number of variables is high and we are working on an implementation study of a design method, it was adjusted for local singularities. Despite this, the design method can be replicated in other locations with different parameter values.

The research method addresses the development of a design science research (DSR) that aims to create a design logic, with its subsequent application in a Brazilian urban space, São José do Triunfo district. We choose the neighborhood, a district of the city of Viçosa, due to its proximity to the researchers of NÓ.Lab - Digital Modeling Laboratory - UFV, Brazil.

The process involves numerous patterns and information organized into plots of subjective, implicit, non-visible knowledge. In this paper, we give visibility to as much as possible of the design logic through data, theoretical inputs, relationship diagrams, and mathematical 
procedures. As the project aims to develop an artifact based on objective data, minimizing the subjectivity of the design process, we selected three main datasets focused on understanding existing local relationships, the definition of the intervention site and the artifact guidelines.

The dataset selected for the development of the design logic was the land use data, collected using a Geographic Information System (GIS), the analysis of the Space Syntax models, the data extracted by the process of operationalization of the book "A Pattern Language", and wood parameters to manufacture the intervention artifact applying Material Based Design concepts.

\section{Data selection}

One of the main reasons for the intervention location choice was the access to a set of georeferenced data about the neighborhood. This data results from an on-site survey carried out for a course taught at the Department of Architecture and Urbanism from the Federal University of Viçosa. Another motivation was the possibility of local community engagement, enabling the residents to become involved in the intervention.

São José do Triunfo is a district of the municipality of Viçosa about $8 \mathrm{~km}$ from the city center. Its population is about six thousand people. Access to the neighborhood is via the highway BR482, which also connects to São Miguel do Anta city.

Unlike other design processes, in this one we start by understanding the object of intervention with the contextual dataset creation step. It aims to create the information set by using a combination of georeferenced data, analyses from Space Syntax, and the book "A Pattern Language" to identify the exact delimitation of the project's intervention area. Using this first data set for the area delimitation is justified because they complement each other; while GIS inserts information about use, land occupation, and urban infrastructure, SS and the Alexander's patterns add certain characteristics about urban layout and spatial qualities based on human behavior (Figure 2).

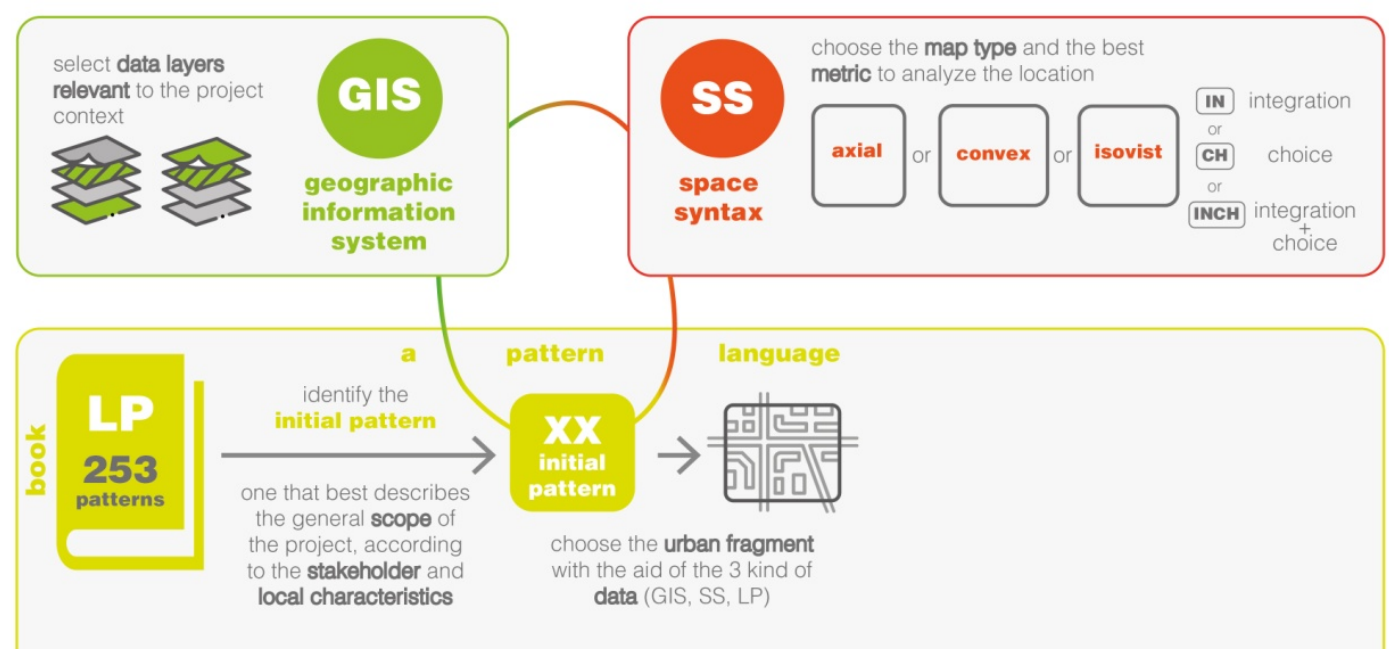

\section{GEOGRAPHIC INFORMATION SYSTEM (GIS)}

The data collection started separating the set of georeferenced data related to the design problem, seeking to identify the most prone areas to the intended type of urban intervention and the most aligned with the project scope. The georeferenced information about the location can be easily found for large and medium-sized cities or result from on-site surveys, like land use, pedestrian flow, urban furniture, green areas, and other information.
Figure 2. Delimiting the urban fragment

Source: Authors 


\section{SPACE SYNTAX}

We justify the option to use Space Syntax (SS) in the design process by the need of a more oriented analysis, understanding the urban layout from a more systemic, mathematical and vectorized perspective. Using SS combined with other data, such as those coming from Geographic Information Systems (GIS), has become an object of study for many urban planners as diagnostic information. A similar method used SS in conjunction with land use and occupation indexes to improve the socioeconomic performance of three Dutch cities (YE; NES, 2014).

From the SS procedures, the designer can choose which of the three SS analyses is most coherent: analysis of the axial space, the convex space or the isovist space. Also, they can choose among other metrics more pertinent to the urban fragment delimitation: choice, integration, or even the integrated metrics. Currently, we can use different software and plugins for these analyses. One of the most common is Depthmap®, which imports files in *.dxf format. The map generated by the software indicates with the warmest color the area with most "movement". Choosing places of greater or lesser "movement" is conditioned by the type of strategy adopted for urban intervention.

\section{A PATTERN LANGUAGE}

As a means of continuing a process with less subjective designer intervention, we adopted the work of Alexander et al. (1977) to guide the places and types of intervention between the areas indicated by the analyzes with SS. In this sense, the option to use the work "A Pattern Language" feeds the design distancing the process from a typological thought. In contrast, the patterns by Alexander et al. (1977) do not bring an idea of interventions and object types. The work "A Pattern Language' has the role of inserting the users' desires, in a situation of impossibility of an effective participatory process. According to Arnstein (1969), a genuinely participatory process takes time. It is subject to constraints, often beyond the control of architects and urban planners.

Alexander et al. (1977) proposed a systematic qualitative characterization of the space offering the designer the possibility of creating an appropriate language for his project, selecting some patterns from the 253 presented by the book. Also, Alexander indicate the possibility of modifying or creating new patterns expanding the network established by the patterns. However, before this selection, the authors propose: 1) Make a copy of the first sequence of patterns that will compose the language; 2) Choose the pattern that best describes the project in mind, the initial pattern. When choosing the initial pattern, the designer qualifies the scope of his design intentions.

On this method, it is possible to delimit the urban intervention area, considering the data collection. The best place indicated by the georeferenced data, weighted against the one indicated by the Space Syntax analysis, and the indication of the initial pattern of the book "A Pattern Language" guides the choice of the urban fragment to be considered in the project.

\section{RESULTS}

\section{URBAN FRAGMENT SELECTION}

The first stage of the design process for choosing the place of intervention combined the use of georeferenced data, the analyses from Space Syntax, and the work "A Pattern Language". We obtained the georeferenced data from the survey done by the students of the Architecture and 
Urbanism course from the Federal University of Viçosa, which applies Geographic Information Systems for data collection, diagnosis, and urban analysis. The students worked in teams to observe the location, mapping the information, including the GPS apps available on mobile devices, and the subsequent creation of data files, which combine spatial entities with an attribute table. They organized the data in two main categories: (1) Urban Infrastructure, characterized by Land Use and Occupation, Road System, Building Template, Urban Furniture, Public Lighting and Urban Drainage System, Institutional Equations, Building Perimeter, Building Limits lots and blocks, among others; (2) Environmental data, characterized by the definition of green and water infrastructure, with mapping of environmental protection areas, main watercourses, topography, green areas, among others. We also included the official data, made available by local, state, and federal entities.

Concerning Space Syntax, we chose angular analysis of segments using the Depthmap® software, using the *.dxf file of the urban layout. Also, we exported the angular analysis and overlaid it on the land use and occupation map, made through georeferenced data (Fig. 6). The Space syntax contribution is this practical experience context being centered on systematic and automated analysis, instead of a subjective design process. In a hypothetical situation of a design process without using SS, the first solution would be selecting the main square and avenue as the place of urban intervention. However, the space syntax angular analysis map indicates that the commercial areas are not necessarily the places of more pedestrian paths, which confirms Hiller's (1984) arguments about natural and total pedestrian movement. Therefore, from this analysis, it emerged an unexpected place of intervention, which opposes the criticism that the SS brings obvious information about space, which is a mistake when working with heterogeneous urban contexts. The square is where public authorities can and want to act, a visible place, but it is not in the everyday path due to its road network location.

By overlaying the use and occupation land map with the best-evaluated segment in the Angular Segment Analysis, it was possible to visualize other places that do not belong to the neighborhood's commercial center. From this overlap, as a second step, we chose the project's intervention limit area and selected one of the patterns from Christopher Alexander's ontology, A Pattern Language.

In the pattern (14) - Identifiable Neighborhood - Alexander et al. (1977) state that people need to feel part of an identifiable spatial unit, evident by three characteristics. (1) Small populations; (2) Small area with a diameter of approximately $300 \mathrm{~m}$ and (3) is not the intersection of a large avenue. We selected the area (Fig. 6) analyzing this $300 \mathrm{~m}$ diameter of the (PL) to incorporate the segment indicated by (SS) and to consider a greater diversity in land use and occupation (GIS). The main challenge in this process was how to weigh these three types of data in the most objective way possible. In an ideal situation of using parametric or algorithmic interfaces, these three data would be project inputs, working together and simultaneously. For this experiment, we decided it analogically. 
Figura 3. Choose of urban fragment $(\mathrm{GIS}+\mathrm{SS}+\mathrm{PL})$

Source: Authors

\section{Urban area from initial pattern 14 - identifiable neighborhood}

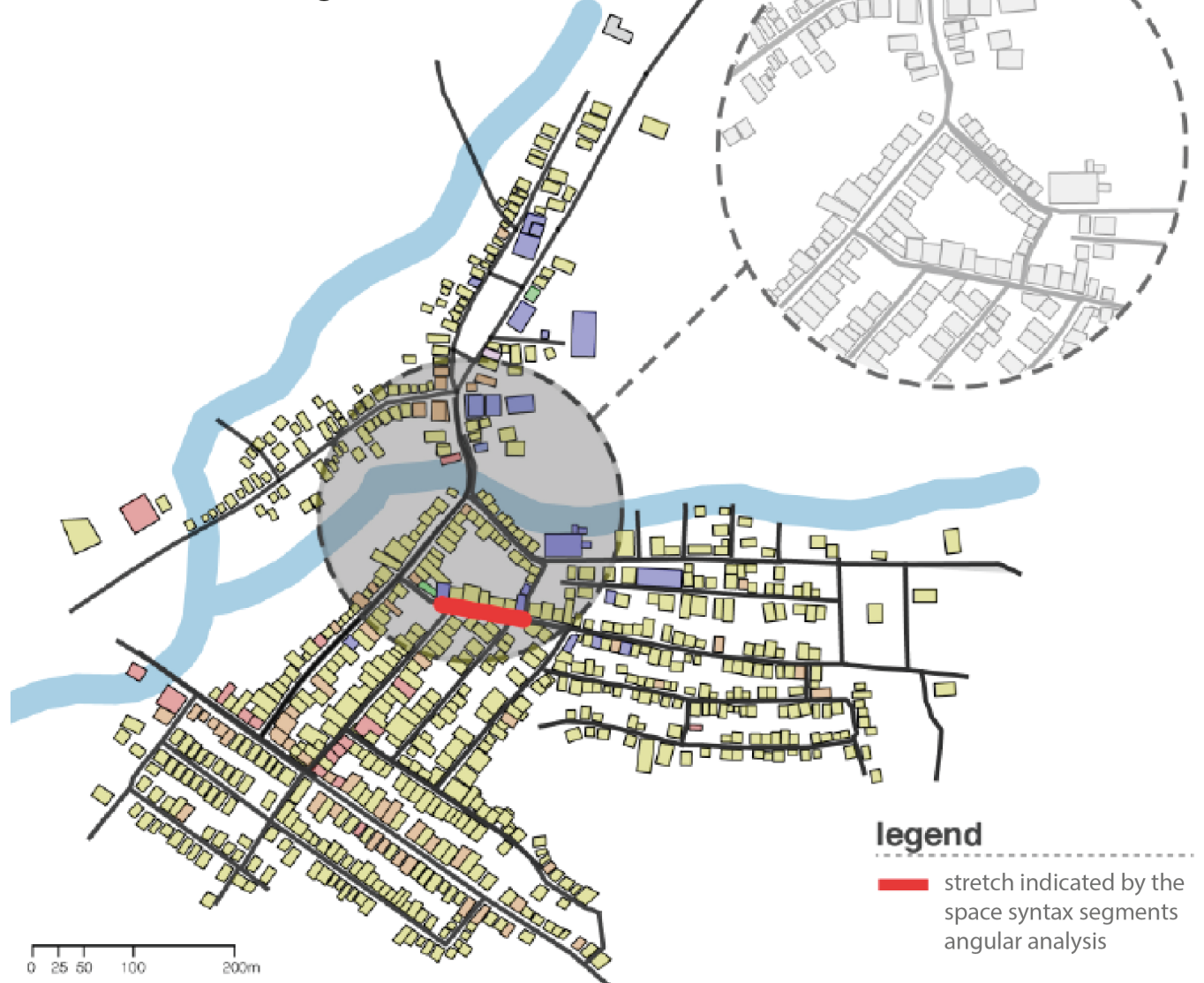

\section{"A PATTERN LANGUAGE" OPERATIONALIZATION}

This operationalization follows some instructions from the beginning of the book "A Pattern Language". The authors indicate that users should choose an initial pattern that best describes the overall scope of the project in mind (Figure 3). In the sequence, we suggested a list of patterns based on this scope, but only those that describe something possible to achieve should be included. In this methodology, these are the "design patterns (DP)". They are those that can be designed by the designers our stakeholders considering their possibilities, and the reality of the place selected for the intervention. According to Park and Newman (2017) it is not clear how discarding patterns and finding which ones are the most active is a laborious task to be performed. Based on this criticism, the most significant adaptation proposed in this method is to use a new classification for the patterns related to network analysis to manipulate them in a more conscious, clear and visual way.

Following the instructions, Alexander et al. (1977) still clarify that the network is open to adjustments by the designer, who can insert new patterns and relations. With the broad information sharing and data available today, the insertion of new patterns has several open paths, which can be incorporated from new realities within cities, buildings and construction techniques, as well as new digital tools. This "personalization" is one of the possible adaptations to mitigate the universal and "romanticized" character attributed to the book. 


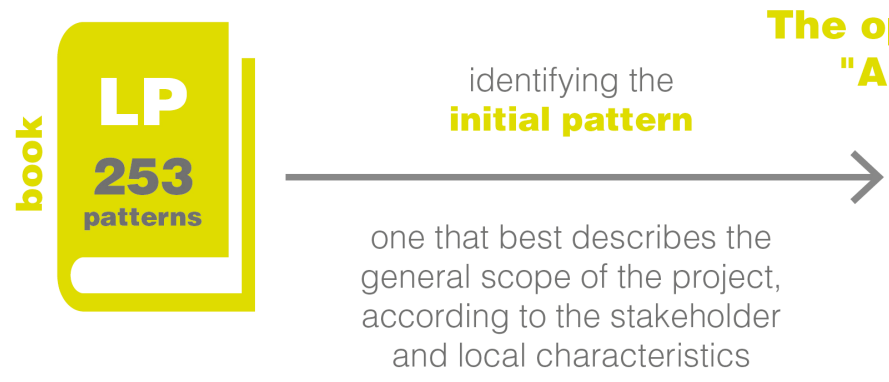

The operationalization of "A Pattern Language"
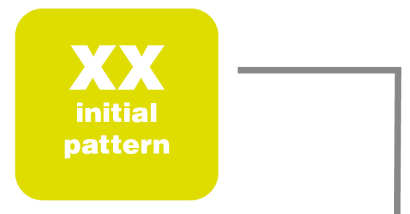

list of

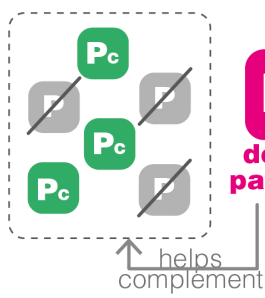

Keep only the patterns that exist in place CP- Context patterns

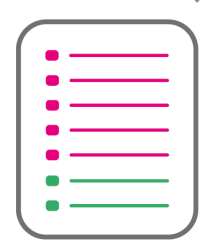

list of patterns design + con-

Some patterns are both contextual and design, as they already exist, even if incomplete and can be designed

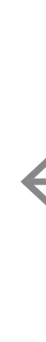

Keep only the possible patterns to stakeholder DP- Design patterns

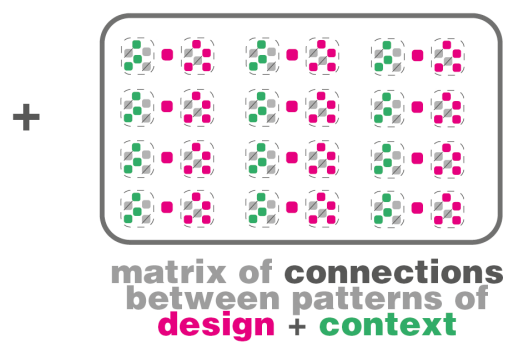

Create the list of connections from the selected design patterns and their respective major and minor filtered patterns. Fron the list of patterns should create a table of nodes and from the list of connections made a table of edges.
Figure 4. The operationalization of "A Pattern Language"

Source: Authors

After the last list of design patterns, the next step is to analyze them individually and identify the connections established in each of them, in which "larger" and "smaller" patterns are connected. The "larger" patterns of each one represent the existing conditions that the pattern can complement, and in this methodology, they will be classified as "context patterns (CP)". In sequence, we filter these larger patterns ("context patterns") eliminating those that cannot be applied to the local reality.

The "smaller patterns" added should be filtered by the same criteria as the design patterns, analyzing the design limitations/possibilities from the actors or stakeholders. Is important to note that the same pattern can be classified as context (CP) and design (DP) at the same time because some characteristics may already exist (i.e., a context pattern), and still can be improved through the project causing it to be parsed as a design pattern. Thus, it is possible to reach a network with local aspects and the contextual reality of the the actors, such as budget, type of intervention, availability of materials and so on.

We converted the connection matrix into two tables: one that contains the nodes (patterns) and the other that contains all the connections already identified considering the direction of the relations, the "smaller patterns" that go in the direction of the "larger patterns", as they are 
the ones that enter the set of larger patterns to complement it. We inserted these two tables in the network analysis software initially to be manipulated by layout algorithms and color assignment for better visualization. The final step is applying the metrics in the network analysis software, to find priority patterns.

\section{NETWORK ANALYSIS}

The most important motivation in using network analytical methods is modeling and analyzing the probability of indirect effects between nodes, as the direct effects could only be evaluated by basic statistics. The notions of distance are fundamental, as they are measured between pairs of nodes and result in a single number. But in some cases, the average distance (density) is not as impressive as the maximum distance (diameter of the network). The maximum distance (diameter) reveals how many edges are necessary to connect the two most distant nodes, while the average distance (density) demonstrates the expected distance between two randomly chosen nodes (ZWEIG, 2016).

Figure 5. Network analysis metrics

Source: Adapted from Gasevic (2014)
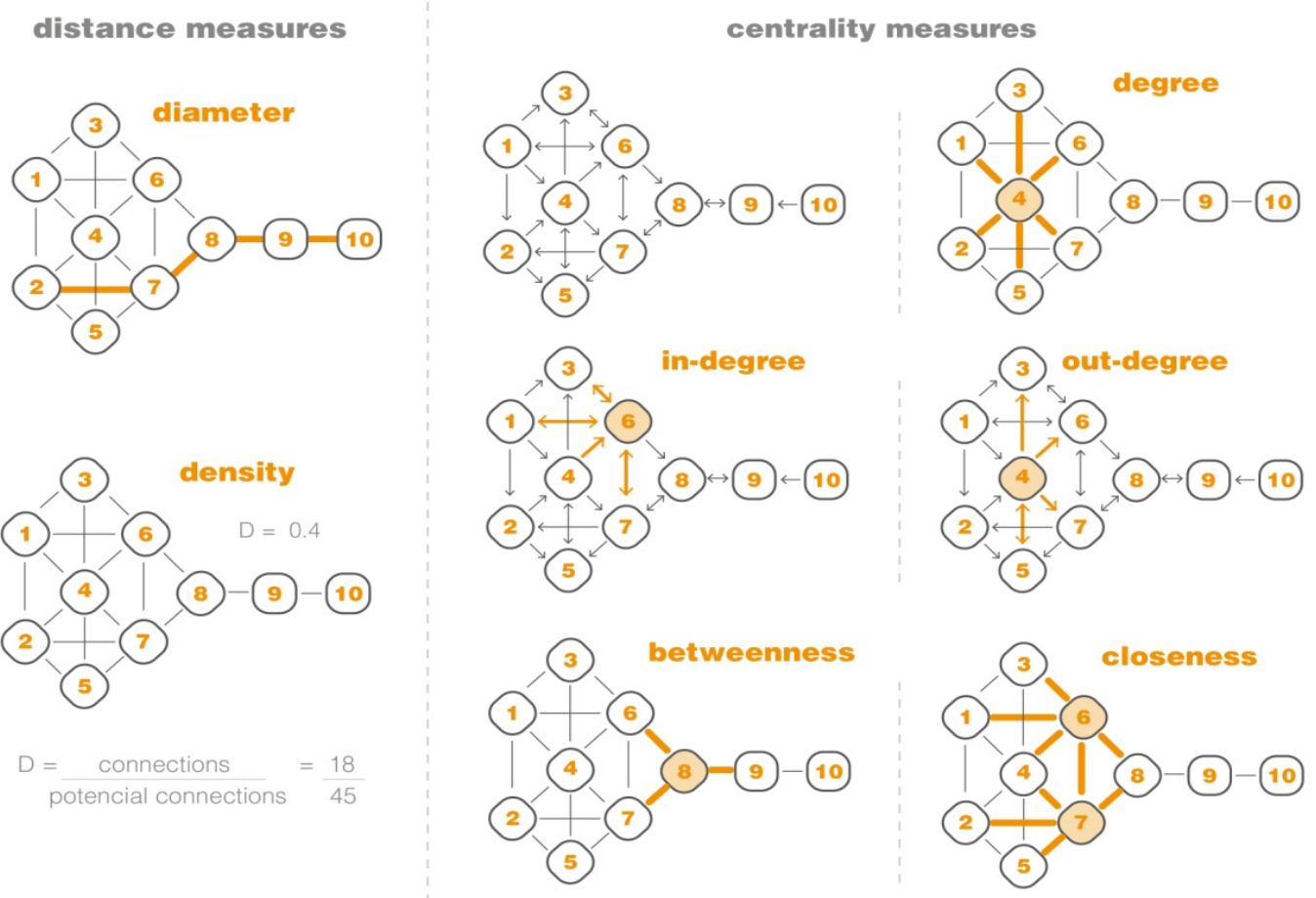

Beyond distance, other important measure is the centrality, which measure the dominance of single nodes or a group of nodes that assume greater importance in the network. The most common centrality measures are degree, betweenness, and closeness centrality. The degree measurement analysis considers the direction in which the connections are made and generates three types of ranking: degree, in-degree, and out-degree. The degree indicates the number of connections that a pattern (node) has with each other; it is the sum of the in-degree and out-degree values. The in-degree measures the number of incoming relations and the outdegree number of relations coming out of that node. Betweenness measures the number of turns a node acts as a bridge along the shortest path between two nodes; it is less about connections, like degree measure, and more about flows. Closeness measures the average 
distance from one node to all others reachable, which are the nodes that are closest to the rest (MATAS; MARTINČIĆ-IPŠIĆ; MEŠTROVIĆ, 2017)

The out-degree was selected for the method because there is a tendency for relationships between nodes with the same degree value (ZWEIG, 2016). The out-degree indicates the number of connections that leave that node, that is, it points out which patterns most help to complement others, whether they are about what already exists in that place, or when they help to complement design possibilities. With this metric, we can visualize the most important patterns in the set logic established by Alexander et al. (1977)but considering the local context.

After we selected the initial pattern and the intervention area, the next step was the selection of the list of design patterns. All of these patterns are consistent with the local context of the $300 \mathrm{~m}$ diameter and with the possibilities of the research group as a stakeholder. We haven't inserted new patterns, but we adapted the 161- SUNNY SPACE pattern, as it does not match the city's weather reality and changed to 161 - SHADED SPACE.

\section{towns buildings}

(25) acess to water
(38) night life
54 road crossing
56 bike paths and racks
(63) dancing in the street
(68) connected play
(73) adventure playground
(93) food stands

\section{construction}

207 good materials

208 gradual stiffening

233 floor surface

238 filtered light

241 seat spots

242 front door bench

243 sitting wall
244 canvas roofs

245 raised flowers

246 climbing plants

247 paving with cracks between the stones

248 soft tile and brick

249 ornament

250 warm colors

251 different chairs
106 positive outdoor space

121 path shape

125 stair seats

160 building edge

161 sunny (shaded) space

174 trellised walk

176 garden seat

177 vegetable garden 203 child
Figure 6. : List of selected design patterns

Source: Authors

Starting from these 32 selected design patterns, we developed the connection matrix, as well as the application of filters for their respective context and design patterns, as indicated in step 3 of the methodology. The insertion of the network in the Gephi software was based on two tables, nodes - class for context and design patterns + edges - source and target.

After generating the basic and unitary metrics of distance - diameter and density - we applied the metric of out-degree centrality (Figure 8) along with the context and design classes highlighted 
Figure 7. Patterns networks on Gephi software with outdegree metric applied

Source: Authors by different colors. The design patterns with the highest out-degree, that is, those that help to complement the preexistence of this 300m "identifiable neighborhood" were (241) SEAT SPOTS and (243) SITTING WALL. They were evidenced with the representation of the node in a larger size. In sequence, some patterns with a high ranking of out-degree: (248) SOFT TILE AND BRICKS, (249) ORNAMENT, (244) CANVAS ROOFS, (176) GARDEN SEAT, (250) WARM COLORS, (242) FRONT DOOR BENCH, (238) FILTERED LIGHT and (174) TRELLISED WALK.

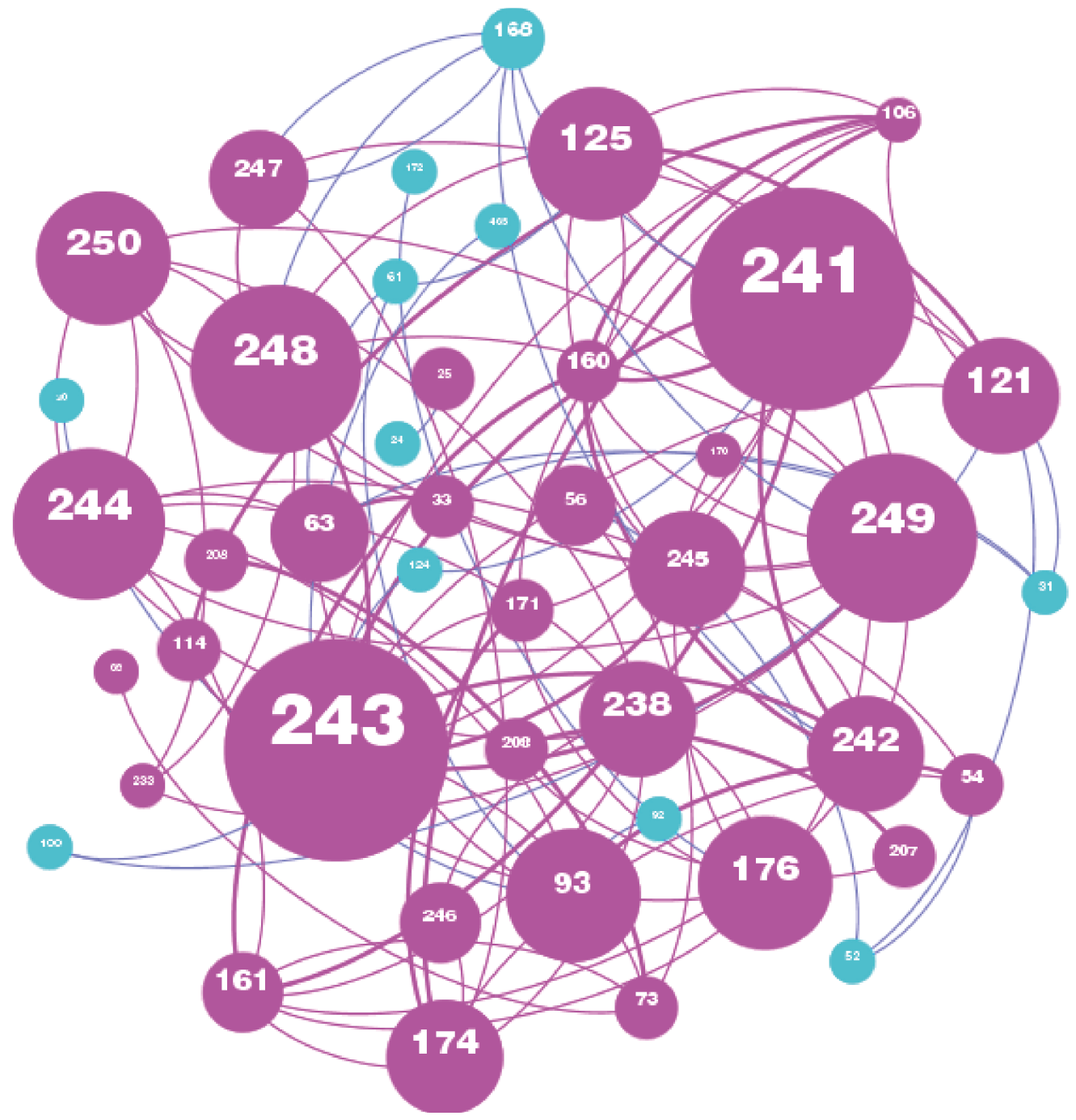

\section{ARTIFACT SOLUTION USING MATERIAL BASED DESIGN}

The richness of Alexander et al. (1977)'s patterns are, for the most part, the composition between the elements, which is not related to a linear succession or addition, but on a set of conditional relations (if/and/or), in tune with parametric thinking and boolean operations. The books' diagrams illustrate this topological model of thought. Also, they include some tectonic features of the objects. In this way, it is possible to insert these parameters of topological and tectonic relations in an algorithmic-parametric interface so we started using Rhinoceros + Grasshopper ${ }^{\circledR}$ to design and prototype objects related to the urban intervention.

A Pattern Language does not focus on the object type, but it still has some tectonic aspects. Therefore, the proposition for the method includes data related to Material Design concepts. With the parameters coming from the book, the designer can design the objects by adding 
visual algorithms that relate to the materiality and tectonics intentions. In this context, this method aims to create a meta-design of configurable design solutions, which allow the variability of objects, on the scale of urban furniture, that act alone, scattered throughout the neighborhood, or together. The goal is not to design a single piece of urban furniture, but to design topological relationships that could adapt to different locations. As a result, we proposed a visual algorithm in Grasshopper that allows us to explore several conditions of small urban interventions, according to "A Pattern Language".

As Material Design is linked not only to computational design but also to digital fabrication, we developed a visual code according to the types of equipment available in the NÓ.Lab Digital Modeling Laboratory and Architectural Department from the Federal University of Viçosa. According to Oxman, (2012) prototyping is a technology that supports digital design based on digital fabrication. It also helps to recover knowledge about materials because it is during the fabrication processes and assembly that some design errors are evident. Once the designer identifies the problems during the prototype manipulation, it is possible to make some improvements and adjustments, obtaining new and better solutions, until the final stage.

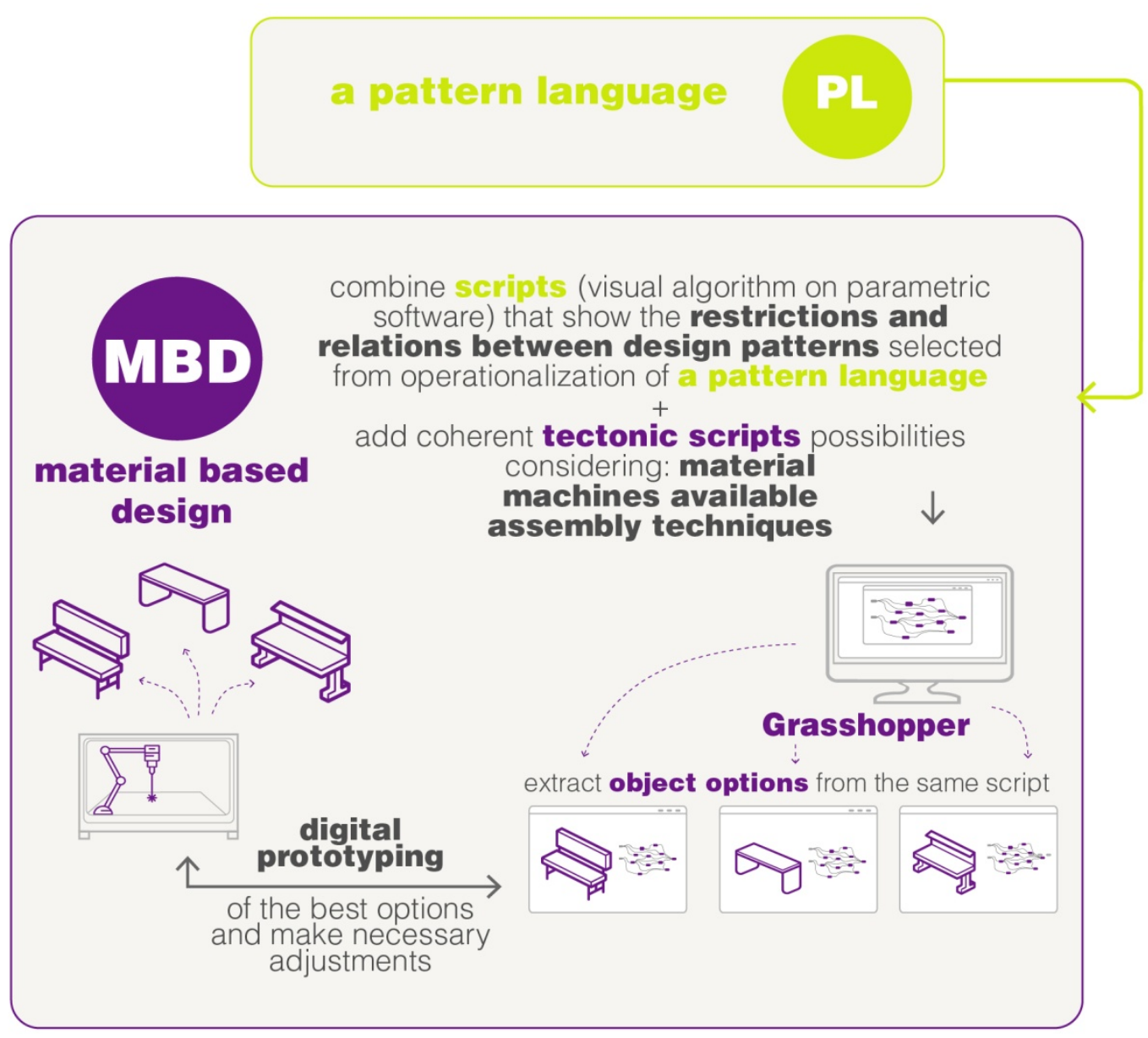

The practical experience of applying the design logic took place in a workshop held at NÓ.Lab Laboratory, documented by audios, videos, and photos. The activities involved professors, researchers, undergraduate, and graduate students, in a collaborative, bottom-up work process, in which the ideas emerged from this joint practice, without hierarchization or separation the member by roles.
Figura 8. Aplication of Material Based Design

Source: Authors 
Figure 9. Workshop final results Source: Authors

We started to outline the architectural object from the patterns with the best ranking in the network analysis. The material chosen for digital manufacturing of the object, within the designers' possibilities, was wood, in 10 millimeters of thick plywood sheets. The material also guided the logic of programming the codes, as slicing the object, based on the wood performance. The design assumptions were: a) the object's tectonics directly related to the material's properties; b) design variations that allow elements with "families" approach; c) furniture that adapts to various patterns of the Language, among the 32 selected and d) a final product aligned with the ergonomic precepts and the metrics presented in the selected patterns.

Then, we developed a visual definition in Grasshopper that allowed the simultaneous use of the construction patterns within those best-ranked: (233) FLOOR SURFACE, (241) SEAT SPOTS, (243) SITTING WALL, (245) RAISED FLOWERS, (249) ORNAMENT and (251) DIFFERENT CHAIRS. These patterns allow several solutions for benches, ways of sitting, outdoor spaces, widening of sidewalks, among others, as a strategy for urban interventions.
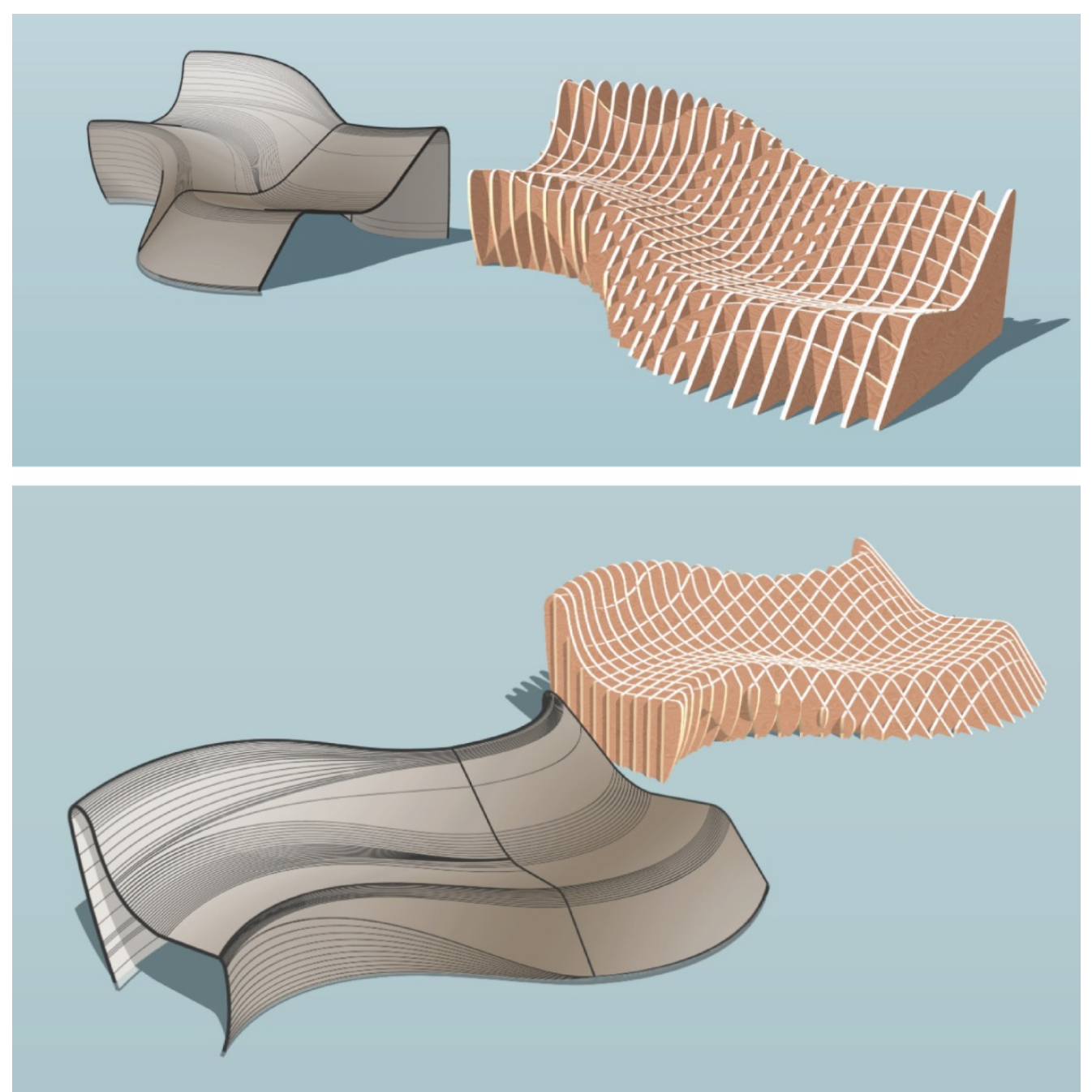

\section{FINAL CONSIDERATIONS}

The article shows the digital design process is not composed of simple automation of routines, nor an isolated change of architect instrumentalization. Decision-making occurs jointly and consciously, combining data at different scales. A design process should add qualities from the 
context of insertion. Also, the choice of the data set must be related to the design decisions and the tools.

One reason for skepticism regarding digital design would be this possible distance from the architect's creative capacity and the user's demands. Then, the architect's conscious role in the process is the coherent choice of the data set. In some cases, the architect finds ways to insert them and allows the users to be a driving force of demand insertion. As the first part of the method proposes the use of georeferenced data, the process is no longer completely hostage to intuitive spatial readings, often biased by occasional visits and random conversations with residents or users. One of the challenges was the treatment and interpretation of data with only an analogical weighting. Data such as Space Syntax could be direct project inputs, in the perspective of future work, in which it is not only analytical but also predictive.

Regarding the operationalization of the book 'A Pattern Language', the notion of a system that makes Christopher Alexander's approach unique, allows multiple and interdependent design solutions, as a part of a more complex set. This interdependence comes close to the topological thinking of the parametric computational approaches, which is related to a meta-design process instead of a final product. The manipulation of relations in graph networks made it possible to visualize and systematize the extensive theory of A Pattern Language, explaining its richness and complexity.

The patterns with the best ranking showed by the network analysis are related to the "sitting in public space" behavior, which can indicate two pieces of evidence. The first one is that the patterns network also showed the nature of the projects extracted from the book and that they are not based on a simple element, such as a bench, but on all the relations that may arise. No coincidence, as Gehl, and Svarre (2013) defend "walking, standing and sitting" as the basic activities of the public space. Another evidence is that the patterns with the greatest raking are almost all on the same scale of intervention, which means they are consistent with what the neighborhood offers at that place and the possibilities that the actors and stakeholders have to intervene there. They are patterns that connect and do not function as isolated elements; for example, they can be benches associated with ornaments and edges of buildings or even gardens with a trellised walk and filtered light. What further reinforces Zweig (2016) argument as a trend, the importance of the relationship between us with the same value degree in more complex networks.

As Zweig (2016) shows, one of the main challenges is transforming data into representation and this is one of the discussions that this study opens: the potential to use the patterns connection logic of "A Pattern Language" and the new classification - "context "and" design " to insert new standards that contemplate contemporary discussions of architecture and urbanism. If we hadn't removed the context patterns from the network, the ranking of design patterns would probably be slightly different and the network less connected to the local reality, which is also important., but we have to take in consideration that the current reality of the world, new materials, digital tools, new forms of interaction, and so many other factors did not exist when the book was written and published. This is, therefore, one of the points of integration and progress for this research.

In turn, the parametric approach to proposing a meta-design for urban furniture is also in line with the notion of building a network of topological relationships, a priori of geometric ones, which brings the logic of A Pattern Language closer to the process algorithmic-parametric computational. However, the research faced the difficulty of building families of objects and breaking the conventional way of conceiving unique solutions. To develop a system of varied possibilities, capable of adapting contextually to different spatial constraints, in each change in the positioning of objects in the public space. In this sense, the biggest challenge is developing a meta-design that accepts the variation of different context inputs and not only of outputs or 
final objects. In this sense, the questions arise: How to anticipate the context demands, even before testing them, to develop an open-source for personalization? And mainly, how to translate and explain in design parameters the subjective data, and less measurable ones?

However, despite the challenges inherent to the process, this investigation opens up to the various possibilities of combining objective data in a computational design process, of the different possible final results, aligned with the search for insertion of the users' demands. For future works, as research is in progress, we intend to deepen into algorithmic-parametric data methods (georeferenced, space syntax metrics, geometric data, among others) in different scales.

\section{Acknowledgments}

This work is funded by FAPEMIG - Fundação de Amparo à Pesquisa de Minas Gerais with the number TEC - APQ-00924-150 and we thank the institution for their support.

\section{Bibliographic References}

ALEXANDER, C.; ISHIKAWA, S.; SILVERSTEIN, M. A Pattern Language: Towns, Buildings, Construction. 1 edition ed. [s.I.] Oxford University Press, 1977.

ARNSTEIN, S. R. A Ladder of Citizen Participation. Journal of the American Institute of Planners, v. 35, n. 4, p. 216-224, 1 jul. 1969.

CARPO, M. The Second Digital Turn: Design Beyond Intelligence. [s.I.] MIT Press, 2017.

DAWES, M. J.; OSTWALD, M. J. Christopher Alexander's A Pattern Language: analysing, mapping and classifying the critical response. City, Territory and Architecture, v. 4, n. 1, p. 17, 19 dez. 2017.

DE KONING, R. E. et al. Strategies for integrated densification with urban qualities: Combining Space Syntax with building density, land usage, public transport and property rights in Bergen city. Proceedings of the 11th International Space Syntax Symposium (SSS 2017), 2017.

DUARTE, J. P. et al. City Induction: A Model for Formulating, Generating, and Evaluating Urban Designs. In: ARISONA, S. M. et al. (Eds.). . Digital Urban Modeling and Simulation. Communications in Computer and Information Science. Berlin, Heidelberg: Springer, 2012. p. 73-98.

GEHL, J.; SVARRE, B. How to Study Public Life. [s.I.] Island Press, 2013.

HE, S. Data-Driven Urbanism: The Balance Between Spatial Intelligence and Design Craftsmanship. Architectural Design, v. 90, n. 3, p. 86-93, 2020.

HILLIER, B.; HANSON, J. The Social Logic of Space. Cambridge: Cambridge University Press, 1984.

JACOBS, J. The Death and Life of American Cities. [s.I: s.n.].

KIM, G.; KIM, A.; KIM, Y. A new 3D space syntax metric based on 3D isovist capture in urban space using remote sensing technology. Computers, Environment and Urban Systems, v. 74, p. 74-87, 1 mar. 2019.

KOLAREVIC, B. Architecture in the Digital Age | Design and Manufacturing. 1st Edition ed. London: Taylor \& Francis, 2003.

KOTNIK, T. On the Role of Geometry in Formal Design. Architectural Research in Finland, v. 1, n. 1, p. 38-47, 17 dez. 2017.

KVAN, T. Data-Informed Design: A Call for Theory. Architectural Design, v. 90, n. 3, p. 26-31, 2020. 
LIMA, F. et al. Avaliação de Intervenções em mobilidade urbana por meio da space syntaz: um estudo na cidade de Juiz de Fora, Brasil. $8^{\circ}$ CONGRESSO LUSO-BRASILEIRO para o Planejamento Urbano, Regional, Integrado e Sustentável. Anais... In: PLURIS. Coimbra: 2018.

LIMA, F. T. DE A. et al. Citymetrics: sistema (para)métrico para análise e otimização de configurações urbanas | Citymetrics: A (para)metric system for the analysis and optimization of urban configurations. Oculum Ensaios, v. 16, n. 2, p. 409-427, 29 maio 2019.

MATAS, N.; MARTINČIĆ-IPŠIĆ, S.; MEŠTROVIĆ, A. Comparing Network Centrality Measures as Tools for Identifying Key Concepts in Complex Networks: A Case of Wikipedia. Journal of Digital Information Management, v. 15, n. 4, p. 203-2013, 2017.

NETTO, V. M. 'What is space syntax not?' Reflections on space syntax as sociospatial theory. URBAN DESIGN International, v. 21, n. 1, p. 25-40, 1 jan. 2016.

OXMAN, R. Informed tectonics in material-based design. Design Studies, v. 33, n. 5, p. 427-455, 1 set. 2012.

OXMAN, R. Thinking difference: Theories and models of parametric design thinking. Design Studies, Parametric Design Thinking. v. 52, p. 4-39, 1 set. 2017.

PAOLETTI, I.; NASTRI, M. (EDS.). Material Balance: A Design Equation. [s.I.] Springer International Publishing, 2021.

PARK, Y.; NEWMAN, G. A framework for place-making using Alexander's patterns. URBAN DESIGN International, 2017.

PICON, A. Smart Cities: A Spatialised Intelligence. Architectural Design Primers. [s.I.] Willey, 2015.

RATTI, C. Space Syntax: Some Inconsistencies. Environment and Planning B: Planning and Design, v. 31, n. 4, p. 487-499, 1 ago. 2004.

SANTOS, A. P. DOS et al. Cidade digital: a construção de shapefiles públicos como ambiente de ensino, pesquisa e extensão. Blucher Design Proceedings. Anais... In: XX CONGRESO DE LA SOCIEDAD IBEROAMERICANA DE GRÁFICA DIGITAL. 2016. Disponível em:

$<$ https://www.proceedings.blucher.com.br/article-details/cidade-digital-a-construo-de-shapefilespblicos-como-ambiente-de-ensino-pesquisa-e-extenso-24805>. Acesso em: 6 mar. 2021

SCHEEREN, R.; SPERLING, D. M. Technological appropriation and socio-technical adequacy in South America: applications of digital fabrication in architecture and design. Blucher Design Proceedings. Anais... In: XXII CONGRESSO INTERNACIONAL DA SOCIEDADE IBEROAMERICANA DE GRÁFICA DIGITAL. 7 nov. 2018. Disponivel em: <https://www.proceedings.blucher.com.br/articledetails/technological-appropriation-and-socio-technical-adequacy-in-south-america-applicationsof-digital-fabrication-in-architecture-and-design-29896>. Acesso em: 7 mar. 2021

VAN NES, A.; YAMU, C. Space Syntax : A method to measure urban space related to social, economic and cognitive factors. [s.I.] Routledge, 2017. p. 136-150

WHYTE, W. H. The Social Life of Small Urban Spaces. New York, NY: Project for Public Spaces Inc, 1980.

YE, Y.; NES, A. Quantitative tools in urban morphology: Combining space syntax, spacematrix and mixed-use index in a GIS framework. Urban Morphology, v. 18, p. 97-118, 1 out. 2014. 
Megg Sousa

sousa.megg@gmail.com

Denise Mônaco dos Santos denise.monaco@ufv.br

Andressa Martinez

andressamartinez@gmail.com

Douglas Souza

dglopes@gmail.com
ZWEIG, K. A. Network Analysis Literacy: A Practical Approach to the Analysis of Networks. Wien: SpringerVerlag, 2016. 